\title{
Mutation at the phenylalanine hydroxylase gene $(P A H)$ and its use to document population genetic variation: the Quebec experience
}

\author{
K evin C Carter ${ }^{1,2}$, Susan Byck ${ }^{1}$, Paula J Waters ${ }^{1,3}$, Brent R ichards ${ }^{1,2}$, \\ Piotr M N owacki ${ }^{1,2}$, Rachel L aframboise ${ }^{5}$, Marie L ambert $^{6}$, E ileen Treacy ${ }^{1,3,4}$ \\ and Charles R Scriver ${ }^{1,2,3,4}$ \\ ${ }^{1} \mathrm{D}$ eB elle L aboratory, M cG ill U niversity-M ontreal Children's H ospital R esearch Institute \\ D epartments of ${ }^{2} \mathrm{~B}$ iology, ${ }^{3} \mathrm{H}$ uman $\mathrm{G}$ enetics, ${ }^{4}$ Pediatrics, M cG ill University \\ ${ }^{5} \mathrm{D}$ epartment of H uman $\mathrm{G}$ enetics, Centre H ospitalier Université L aval, Ste Foy, Q uebec \\ ${ }^{6} \mathrm{D}$ epartment of H uman $\mathrm{G}$ enetics, $\mathrm{H}$ ôpital Ste Justine, M ontreal
}

\begin{abstract}
We describe variation at the $P A H$ locus in the population of Quebec. We successfully analyzed 135 of 141 chromosomes from phenylketonuria (PKU) probands (95.7\% of the sample), and eight additional chromosomes from a small number of probands with non-PKU hyperphenylalaninemia (HPA). The full set of chromosomes harboured 45 different $P A H$ mutations: i) seven polymorphisms (IVS2nt19, IVS3nt-22, IVS6nt-55, Q232Q, V245V, L385L, Y414Y); ii) four mutations causing non-PKU HPA (T92I, E390G, R408Q, D415N); iii) 34 mutations causing PKU. Only six mutations (M1V, R261Q, F299C, S349P, $\mathrm{R} 408 \mathrm{~W}$ and IVS12nt1) occurred in the whole province at relative frequencies $>5 \%$; most are rare and probably identical by descent. By studying associations of mutations with polymorphic haplotype alleles, we found examples of mutations on different haplotypes that were identical by state, but not by descent because they were recurrent mutations (E280K and R408W); and examples of mutations identical both by state and by descent because of intragenic recombination (S67P, G218V, V245A and IVS12nt1). Ten mutations were first described in Quebec and five are still unique there; three of these 'Quebec' mutations are reported here for the first time (c.125A $\rightarrow T$ (K42I); [c.470G $\rightarrow \mathrm{A} ; \mathrm{c.471A} \rightarrow \mathrm{C}$ ] (R157N); c.707nt-55 (IVS6nt-55). The PAH mutations stratify by geographic region and population, their distributions validating hypotheses about European range expansion to North America during three separate phases of immigration and demographic expansion in the Quebec region over the past four centuries. The $P A H$ homozygosity value $(j)$ is 0.06 for the total Quebec sample (0.5-0.08 by regions), and the corresponding homoallelic fraction of mutant $P A H$ genotypes is $24 \%$. These findings are a documentation of genetic diversity in the Quebec population.
\end{abstract}

Keywords: mutation; phenylalanine hydroxylase gene (PAH); hyperphenylalaninemia; phenylketonuria; population variation

Correspondence: $C R$ Scriver, DeBelle Laboratory, $R \mathrm{~m}$. A -721, M CG ill University-M ontreal Children's Hospital R esearch Institute, 2300 Tupper Street, Montreal, Q uebec $\mathrm{H} 3 \mathrm{H}$ 1P3, Canada

R eceived 11 J uly 1997; revised 9 September 1997; accepted 15 O ctober 1997 


\section{Introduction}

Range expansion by Europeans has been a major demographic feature of human history in the current millennium. ${ }^{1}$ Three separate phases of E uropean settlement occurred to account for the richly diverse history of the region of N orth A merica called Q uebec, where resides one of the best documented populations in the world. ${ }^{2-6}$ French settlers came before 1759; L oyalists from the $U$ nited States and emigrants from the $U$ nited K ingdom came after 1759; non-French, non-British settlers arrived in substantial numbers after 1945. D escendants of these settlers are the majority among the nearly 7 million persons comprising the population of $Q$ uebec today, and among them are probands with hyperphenylalaninemia (HPA) due to impaired function of phenylalanine hydroxylase enzyme. The corresponding gene (symbol PAH) has been cloned and characterized: ${ }^{7-10}$ rare mutations in it cause disease, notably phenylketonuria (PKU), ${ }^{11}$ and the diseasecausing alleles are widely ascertained by screening newborns for HPA. The probands described in the present report were ascertained in this manner. A ccordingly, their allelic variation at the $\mathrm{PAH}$ locus could be used as markers for the demographic sources of and genetic variation in the population of $Q$ uebec.

The PA H gene harbours over 328 different mutations (see http://www.mcgill.ca/pahdb); it also has a set of polymorphic alleles in apparent linkage disequilibrium from which polymorphic haplotypes can be generated. ${ }^{10,12-16} \mathrm{M}$ utations and polymorphic haplotypes, along with descriptors of attributes and relationships, are recorded in a relational database (PA Hdb) curated and maintained on behalf of the PAH Mutation A nalysis Consortium. ${ }^{17}$ In the present report, the fourth in a series, ${ }^{18-20}$ we describe 45 different PAH mutations in probands with HPA, some causing PKU, others causing non-PKU HPA, all ascertained by newborn screening in the Quebec population over the past 20 years; they include ten novel mutations first identified in this population. Some mutations, otherwise identical-by-state, provided evidence for recurrent mutation or intragenic recombination to explain their distribution on multiple polymorphic haplotype backgrounds. PAH mutations stratify in Quebec by geographic region and population history. A ccordingly, our findings have historical and medical as well as genetic interest.

\section{Materials and Methods}

The Sample

From a recent epidemiological analysis ${ }^{21}$ of newborn screening in Quebec between 1973 and 1990, we ascertained probands with HPA and subdivided them into PKU (classical and variant forms) or non-PKU HPA. The criteria for classification are described elsewhere. ${ }^{11}$ We obtained sufficient DNA from 141 independent chromosomes in probands with PKU and completed analysis on 135 (95.7\% of the sample). In a related project, we began the analysis of chromosomes from 13 probands with non-PKU H PA; data on eight chromosomes are included here for comparison with the set of PKU-causing mutations. There are no probands of A boriginal, O riental or A frican ancestry in the sample. The project was reviewed and approved for ethics by the Institutional R eview B oard (M ontreal Children's Hospital).

Geographic Features We stratified findings by geographic region. 'E astern $Q$ uebec' is the settled region east of the city of Three R ivers; its population is French Canadian, with a well-documented pattern of settlement and expansion. ${ }^{22,23}$ 'Western Q uebec' is the corresponding region west of the river; it has a largely French $C$ anadian population and a demographic history different from that in E astern Q uebec. 'Montreal' refers to the region of greater Montreal and environs, where the non-French Canadian component of the Q uebec population is predominantly located. The DNA samples were obtained from probands attending the regional medical centers at Laval, M ontreal and McG ill universities respectively.

\section{Mutation Detection}

We used 'broad range', denaturing gradient gel electrophoresis (DGGE) to analyze all exons and flanking regions of intron sequences in the PA $H$ gene, after amplification by PCR from designated GC-clamped primers. ${ }^{24,25}$ M utant exons were amplified with non-clamped primers, and sequenced using the dsDNA cycle sequencing system (Gibco BRL). Novel mutations were confirmed on second PCR sample by sequencing, selective restriction analysis, artificially created restriction sites, or hybridization with allele-specific oligonucleotides.

Mutations are named ${ }^{26,27}$ using the convention of the PAH Mutation A nalysis Consortium, i.e. by 'trivial names' which describe the effect of the allele on gene transcription and translation; the corresponding systematic (nucleotide) names are given in the PAH Mutation D atabase.

\section{Haplotype Analysis}

We used seven diallelic (RFLP) and two multiallelic polymorphic sites at the PAH locus ${ }^{12,13,15}$ to describe the relationships with mutations and haplotype background, as described previously. ${ }^{20}$

\section{Calculation of Homozygosity (j)}

Homozygosity (j) at the PAH locus was calculated for the whole population and for each regional population by the formula $j=\Sigma x_{i}^{2}$, where $x_{i}$ is the frequency of each allele; the uncharacterized alleles (chromosomes) were given the frequency $1 / N$ where $N$ is the total number of mutant chromosomes. 


\section{The PAH Mutation Database}

This curated locus-specific mutation database ${ }^{17,28}$ is relational in design and contains information on over 328 different mutations (entities), with attributes, relationships (eg to haplotypes and populations), and other details. Data are copied from PA Hdb (L ogical V iews) and periodically posted on the Internet (http://www.mcgill.ca/pahdb). A search engine is now available (Nowacki P, K Hechtman, CR Scriver unpublished data). We used the database to compare findings in Quebec and elsewhere.

\section{Terminology}

The term 'disease-causing' implies mutations causing hyperphenylalaninemia (H PA). The terms 'chromosome', 'allele' and 'mutation' are used both according to their conventional definitions ${ }^{29}$ and in particular contexts here. Chromosome is the operative word describing the physical source in the blood sample of the DNA analyzed at the PAH locus (chromosome 12q24.1). M utation is the equivalent of muton ${ }^{29}$ and refers to the smallest unit of DNA changed in the PAH nucleotide sequence; each mutation is named according to convention $^{26,27}$ (see also http://www.mcgill.ca/pahdb). A llele, as in 'heteroallelic genotype', means the proband inherited two different mutons in trans at the PAH locus; homoallelic implies identical mutons. A mutation may be identicalby-state on different chromosomes (alleles) but not identical- by-descent; we used mutation-haplotype associations (alleles) to distinguish mutations identical-by-state from those identical-by-descent.

\section{Results}

\section{The PAH Mutations in Quebec}

We identified 45 different PAH mutations on 135 PKU chromosomes and on eight additional non-PKU HPA chromosomes in the Quebec probands (Figure 1). Seven mutations, each unlikely to be disease-causing, were found in cis with a disease-causing mutation; they are: i) three apparent polymorphisms in introns of which two were previously known (IV S2nt19t $\rightarrow$ c and IVS3nt-22c $\rightarrow$ t) and the third, heretofore unknown (IV S6nt-55t $\rightarrow$ c); ii) four silent polymorphisms in codons (Q 232Q , V 245V, L 385L, Y 414Y), all previously known and each useful as an intragenic marker.

The other 38 mutations are apparently diseasecausing, many having been analyzed by in vitro expression analysis ${ }^{30}$ as indicated in Table 1; i) four are
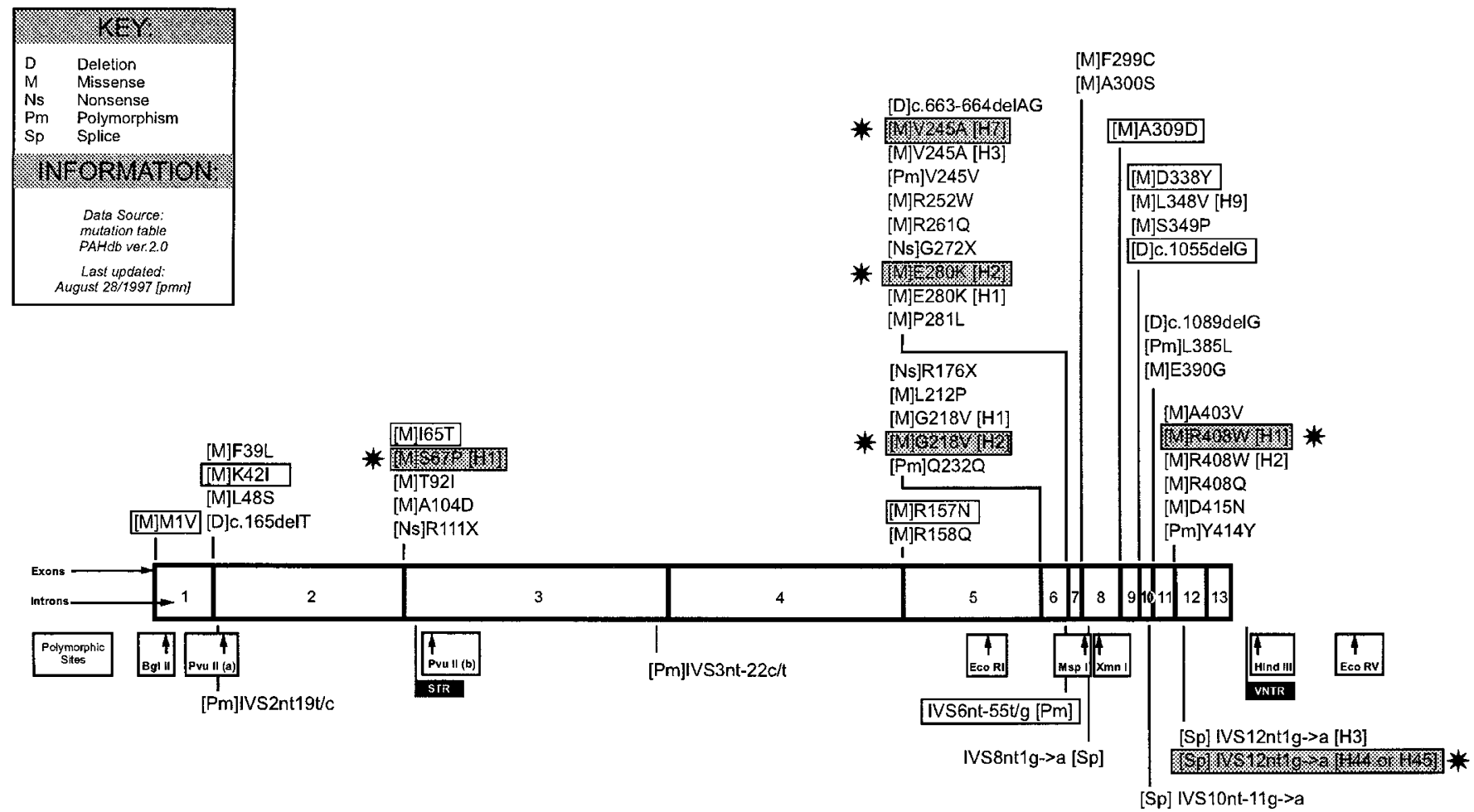

Figure 1 The human PAH gene ( $\sim 100 \mathrm{~kb}$ on chromosome 12q24.1) showing distribution of exons (bars) and introns (white boxes). B elow the gene is shown the relative position of diallelic (open boxes) and multiallelic (shaded boxes) polymorphic markers used to construct haplotypes. Forty-five different mutations on $\mathrm{Q}$ uebec chromosomes are shown. Polymorphic mutations are indicated; the remainder cause hyperphenylalaninemia (HPA): PKU ( $n=34)$, or non-PKU HPA (T 92I, E 390G, R 408G, R 408Q, D 415N). $M$ utations that are identical-by-state and found on more than one haplotype ('alleles') are shown in shaded boxes with star. A II boxed mutations were first identified in Q uebec. Symbols: fs, frameshift; [H ], haplotype; numbered as described elsewhere ${ }^{53}{ }^{\circ} 1997, \mathrm{PA}_{\mathrm{H}}$ M utation A nalysis Consortium 
Table 1 PKU -causing PAH mutations (and alleles) on chromosomes in Quebec:a relative frequencies (\%) and distributions by geographic region

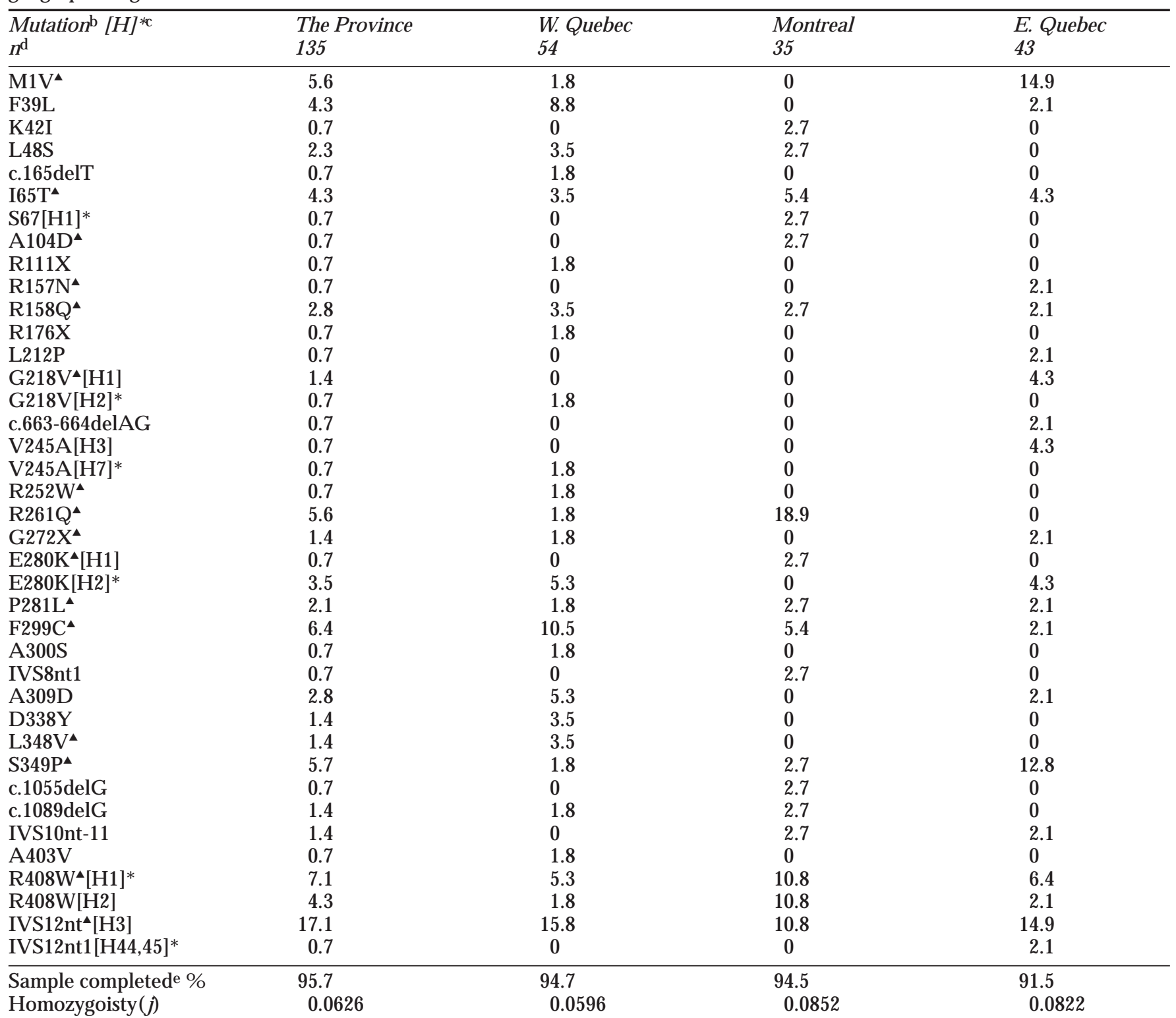

aComposite data for all phases of the project (see M ethods).

bThe following 33 mutations, reported in France or French populations47, 54, 55 identified in the PAH mutation database, were not found in the Quebec sample of PKU and non-PKU HPA chromosomes: F55L, IV S2nt5, R 68S, P89fs, c.283delATC (dell94), H 146Y, I144T, G 171A，E178G，Y 198fs，G 239S，R 241C，R 241H，R2430 R 243X，L249F，R 2520，A 259V，C265G，S273F， Y 277D, S303P, L311P, P314H， F331L， c.1043del11bp, S350T, c.1066-3c $\rightarrow$ t(IV S10nt-3) c.1117delG C(A 373fs), E 390G, c.1199+1g $\rightarrow$ a(IV S11nt1), c.1220delc(P407fs), R 413S, Y 414C

'Some mutations were found to be identical-by-state on two different haplotype backgrounds (see text).

*indicates the novel association found in Q uebec.

$d_{n}=$ number of chromosome successfully analyzed with disease-causing mutation identified.

eThe denominators for calculating percentage of chromosomes successfully analyzed are the original sample sizes: Province, 141;

W. Q uebec, 57; M ontreal, 37; E. Q uebec, 47.

$\triangle \mathrm{M}$ utation has been expressed in vitro to confirm an effect on PA H catalytic activity; see 30. 
associated with non-PKU HPA of which three (T92I; E 390G ; D 415N) occurred in 'functionally hemizygous' (missense/null) genotypes and the fourth (R 408Q) in the homoallelic state; $i i)$ the remaining mutations $(n=$ 34 , Table 1) are all associated with PK U and account for $95.7 \%$ of the PKU chromosomes analyzed here. Five mutations were identical-by-state on different haplotype backgrounds but not necessarily identicalby-descent (see below). M utations yet unidentified are not likely to be those undetectable by DGGE, such as large deletions (rare in the PA H gene), but they may be located in untranslated regions ( $5^{\prime}$ region or introns) affecting expression in ways yet to be analyzed.

The PAH mutation database records 54 diseasecausing (PKU) mutations in populations designated as 'France' or 'French'; 33 of these have not yet been found in the Quebec population (Table 1, footnote). Twenty-one of the 'French' PAH mutations and many other 'European' alleles were found in Quebec probands.

\section{Mutations and Alleles Particular to Que-} bec Ten mutations in the set of 45 in Q uebec (Figure 1) were identified first in this population; five were subsequently found elsewhere: M IV in France; I65T in $G$ reat $B$ ritain, I reland, Western E urope, Iberia, and in Europeans who emigrated to Australia, and South A merica; A 309D in N. I reland; c.1055delG in B elgium, Germany and North A frica; R 408W on haplotype 1 in N orthwest $E$ urope and in E uropeans who emigrated to $\mathrm{N}$ orth A merica and A ustralia (see PA H database). The other five mutations (K 42I, R 157N, E 280K on haplotype 2, D 338Y and IV S6nt-55) remain unique to Q uebec as of September 1997.

Novel Mutations Three mutations are reported here for the first time (data seen by reviewers and documented formally elsewhere). ${ }^{31}$ Two are diseasecausing: c.125A $\rightarrow T$ (K 42I) on haplotype 21; and [c.470G $\rightarrow A ; c .471 \mathrm{~A} \rightarrow \mathrm{C}$ ] (R 157N) on an undetermined haplotype. Each occurred on a single chromosome. $\mathrm{K} 42 \mathrm{l}$ occurred in a proband with classical PKU in a 'functionally hemizygous' PAH genotype ( $\mathrm{K} 42 \mathrm{I} / \mathrm{E} 280 \mathrm{~K}$ ). The R 157N mutation, found in a patient with PKU, involves a dinucleotide substitution and it curtails the measured activities of PA $\mathrm{H}$ enzyme both in vitro and in vivo. ${ }^{32}$ The third allele is a polymorphism (IV S6nt-55a/c); it was found on three different PKU and control chromosomes (relative frequency $1.4 \%$ ). Whether it has any effect on phenotype is not known.
Unusual Identical-by-State Mutations Four PKU -causing mutations were found, in this phase of the project, to be identical-by-state on two different polymorphic haplotype backgrounds (Figure 1, Table 1). Three of the novel relationships (S67P on haplotype 1 vs haplotype $4,33,34 \mathrm{G} 218 \mathrm{~V}$ on haplotype 2 vs haplotype $1{ }^{24}$ and V 245A on haplotype 7 vs haplotype $3^{35}$ ) can each be explained by a single intragenic recombination (data shown elsewhere). ${ }^{31}$ The fourth mutation (IV S12nt1) was found on either haplotype 44 or 45 ; this unique association (IVS12nt1 is otherwise almost exclusively on haplotype 3 ) is unresolved because of technical difficulties with the E coRV site; nonetheless, a double intragenic recombination would be necessary to explain it.

Two other identical-by-state mutations with unusual haplotype relationships, each first reported in Q uebec, were found again in this phase of the project (Table 1). They are R 408W on haplotype $1^{18,19}$ and E280K on haplotype $2{ }^{20}$ In both cases, the finding is compatible with recurrent mutation involving a C PG site. ${ }^{36,37}$

Mutational Heterogeneity in Quebec The observed frequency of homoallelic PK U genotypes was $24 \%$. We used the sets of PKU-causing mutations (Table 1 ) to calculate homozygosity (j) at the PAH locus for the Quebec population as a whole and by region. The value for $Q$ uebec is 0.06 ; values are slightly higher in the $M$ ontreal and eastern regions and lower in Western Q uebec.

\section{Mutation Types in Quebec and the World}

The relative frequency distributions of mutation types are similar in Quebec and the world (Figure 2). The great majority of mutations are missense. PAH deletions rarely involve more than one or a few nucleotides (http://www.mcgill.ca/pahdb). Insertions are also small and there are none in the Q uebec sample. Polymorphisms are not included in Figure 2 because they are underestimated in the world sample whereas their detection has been efficient using DGGE in the Q uebec sample.

\section{Effect of Mutations on Phenotype}

Whether all 34 mutations associated with PKU (Table $1)$, or the four mutations associated with non-PKU HPA inherited in functionally hemizygous or homoallelic genotypes (T92I, E 390G, R 408Q, and D 415N, Figure), impair PAH enzyme function in vivo is unknown. However, 16 of the PKU mutations and one non-PK U H PA mutation ( $R$ 408Q) have been studied in 
vitro by expression analysis $s^{30,32}$ and Table 1 ; they all impair catalytic activity. By their nature, the other 20 mutations are also likely to alter PA H enzyme activity. The corresponding in vivo genotype-phenotype relationships have been documented in detail elsewhere ${ }^{38}$ (see also PAH database). Whether all of those designated as neutral polymorphisms are without any phenotypic effect is unknown.

\section{Geographic Stratification of Alleles}

There is non-random distribution of PAH alleles by geographic region in Q uebec (Table 1) and the 12 most prevalent mutations (PKU and non-PKU HPA causing) stratify by geographic region (Figure 3 ). The

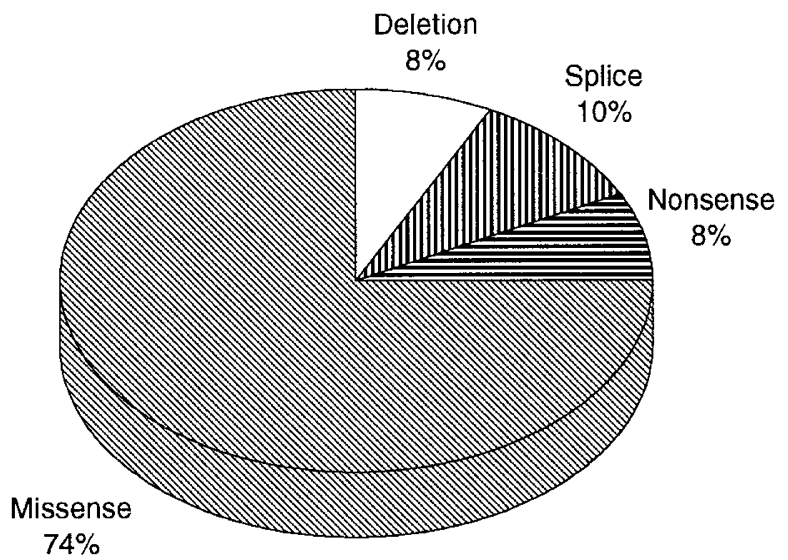

Quebec Mutations

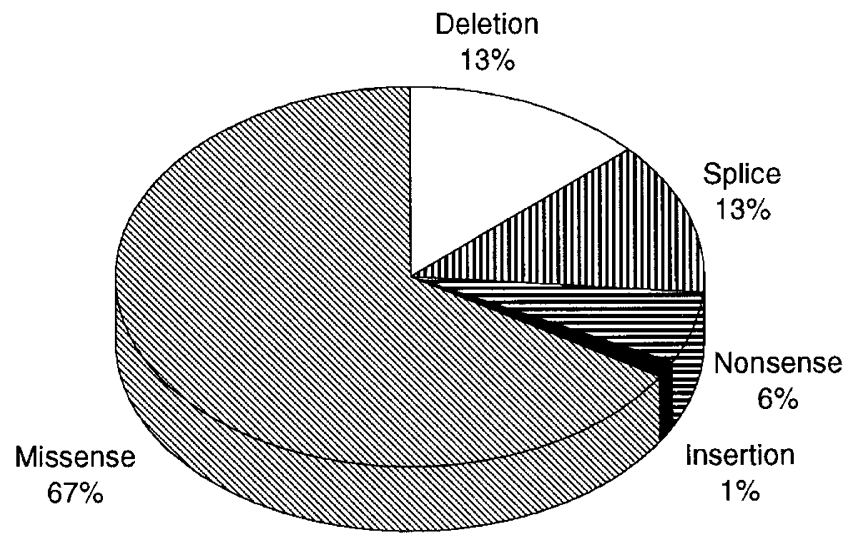

World Mutations

Figure 2 The Quebec PAH mutations excluding polymorphisms, classified by type and compared with the world wide set $(n=328)$, the latter taken from the PAH mutation database (http://www.mcgill.ca/pahdb) distributions are compatible with different demographic histories for the three regions.

\section{Discussion}

Hereditary metabolic diseases, albeit individually rare in prevalence, are important sources of knowledge about human genetic disease in general. From mutation detection by current methods, ${ }^{39,40}$ each of the corresponding loci has revealed extensive locus-specific allelic variation. Whereas a few mutations at each locus may be prevalent and shared widely among probands, most disease-causing mutations are rare, their histories coinciding with those of families and defined populations and probably identical by descent. ${ }^{41}$ The record of mutations in the PAH gene is no exception to this emerging view.

Probands with hyperphenylalaninemia, notably PKU, are being ascertained with high efficiency wherever newborn screening takes place. A ccordingly, the sample of mutant chromosomes available for analysis of the PAH gene is large, worldwide, originates in the populations of at least 28 countries, and harbours more than 328 different mutations. ${ }^{17}$ When these $\mathrm{PAH}$ mutations are analyzed for their relationships with polymorphic haplotypes, populations of origin, and geographic distributions, ${ }^{42}$ the majority that are disease-causing are indeed rare; no more than five being prevalent among Europeans: they are I65T, IV S10nt11, IV S12nt1, R 408W on haplotype 1 and R 408W on haplotype 2 (the latter a recurrent mutation) ${ }^{36}$ and they account for about two-thirds of the known European $\mathrm{PAH}$ mutations. Whereas the aggregate frequency of PKU mutations is only about $1 \%$ in European genomes, $^{11,43}$ individually they are useful markers of human history, ${ }^{42}$ notably of E uropean range expansion to A ustralia, ${ }^{44}$ South A merica ${ }^{45}$ and North A merica. ${ }^{46}$ We can now see how their presence in Quebec populations reflects a well-documented range expansion in three different phases after 1600 A D, first from France, then from $G$ reat $B$ ritain, and lately from other regions of Europe and the world. The Quebec $\mathrm{PAH}$ mutations (Figure 1) validate demographic and historical hypotheses and interrogate mutation mechanisms.

The rare (disease-causing) and polymorphic (neutral) alleles on PKU chromosomes in the Quebec population (Table 1), tell us the following:

i) The majority ( $>80 \%$ ) of the phenotype-modifying (disease-causing) mutations occur at low 
relative frequency $(q<0.035)$ and one third occurs at frequencies below 0.01; among these are the novel mutations (Table 1). No mutation in Q uebec occurs at frequencies above 0.18 , but five of the 36 PKU mutations account for half of those in the population. These findings are in keeping with emerging views of human genetic variation. ${ }^{41}$

ii) Some PAH mutations, known to occur at higher relative frequencies in European populations today, are distributed in all regions of Q uebec at corresponding frequencies, eg IVS12nt1 and R 408W (Table 1). Other mutations, found in Quebec at the higher frequencies, are non- randomly distributed (stratified by region) (Table 1, Figure 3), eg MIV and S349P in eastern Q uebec; R 2610 and R 408W in Montreal; F 39L and F299C in western Quebec. These particular mutations appear to be tracers of historical demography, reflecting the stages of European range expansion to the $\mathrm{N}$ ew World: from France before 1759 (eg M IV), from the British Isles in the second phase after 1759 (R 408W on haplotype 1) and from central and southern Europe after 1945 (eg P281L and IV S10nt-11).

iii) The distribution of various PAH alleles in French Canadians is compatible with founder effect and genetic drift, for example: a) M $1 \mathrm{~V}$, a rare allele in

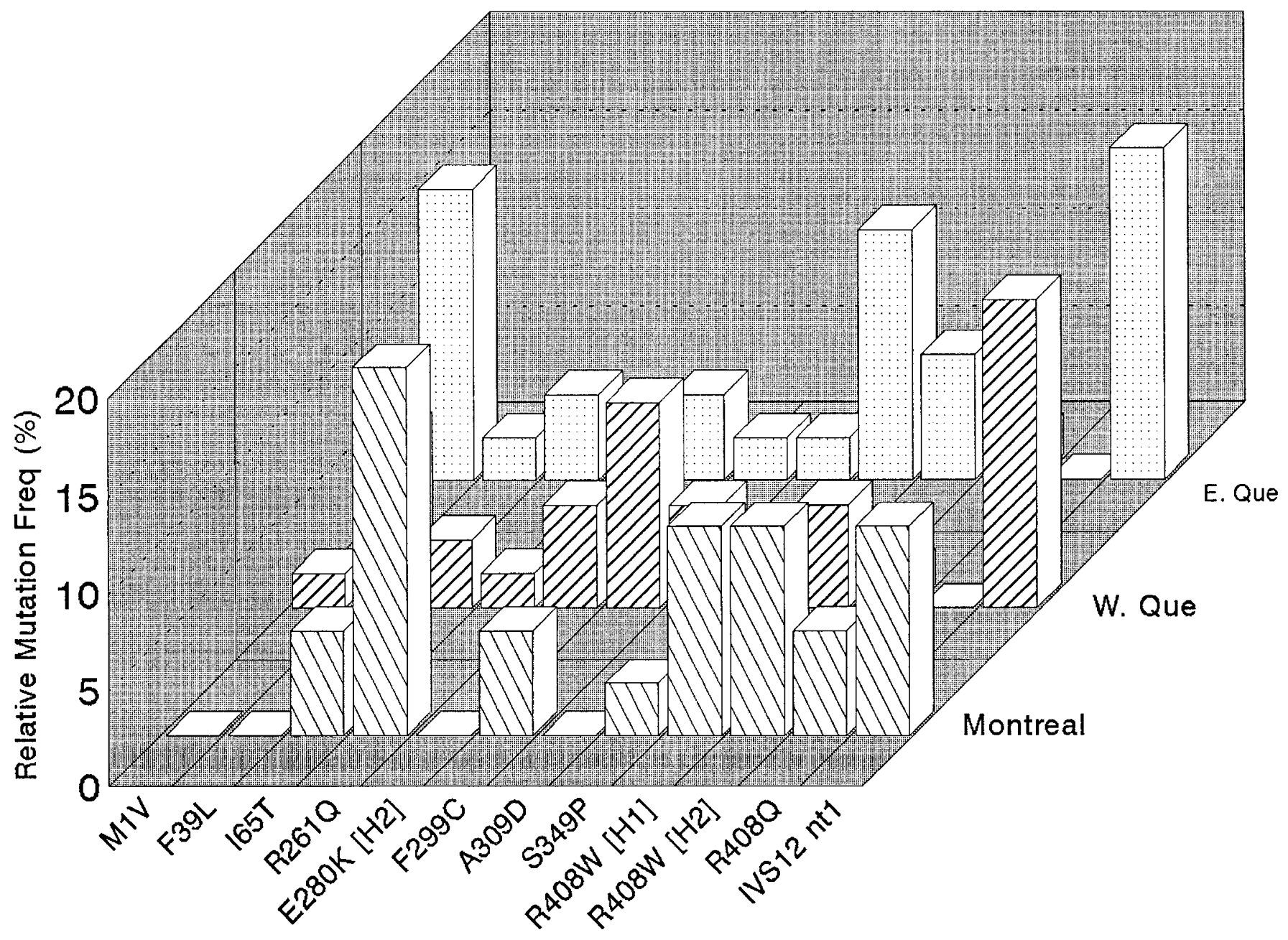

\section{Mutations}

Figure 3 PAH mutations in PKU probands stratify by geographic region (place of birth) in Quebec. The most prevalent alleles in each region are plotted as relative frequencies in the region; R 408Q associates with the non-PK U H PA phenotype, the remainder with classical PKU. Geographic regions are defined in M ethods 
France today, ${ }^{47}$ and unknown in Europe outside of France, has been traced to ancestors who emigrated from a small region in north-western France $^{48}$ who contributed disproportionately to the gene pool in the north-eastern region of $\mathrm{New}$ France (Q uebec) $;{ }^{49}$ b) among 54 different PKU mutations found in French populations today, 33 have not been found in Q uebec.

iv) The high mutation detection rate on Q uebec PK U chromosomes $(95.7 \%)$ permits us to estimate homozygosity values in this population where the observed fraction (about one quarter) of homoallelic PKU genotypes is similar to that found in E urope and elsewhere. The corresponding homozygosity value ( $\mathrm{j}$ ) for the $\mathrm{Q}$ uebec population as a whole, and for each of the regional geographic regions, is low $(j<0.1)$. The $Q$ uebec values are similar to those for the U nited States, the N etherlands and Victoria (A ustralia) - typical outbred populations - and lower than those for Poland (0.44), I celand (0.26), Tataria (0.19) and D enmark (0.17) for example; ${ }^{46}$ the myth of inbreeding in Q uebec appears contradicted here.

v) The Q uebec project has generated useful hypotheses about the molecular mechanisms underlying mutations at the PA H locus, for example: a) from the discovery of European mutations identicalby-state but on multiple haplotypes in the Q uebec population (eg R 408W on $\mathrm{H} \mathrm{I}^{18}$ and $\mathrm{E} 280 \mathrm{~K}$ on $\mathrm{H} 2)^{19}$ came evidence for recurrent mutations at CpG dinucleotides in the gene. ${ }^{36,37}$ These findings encouraged an analysis of predicted mutability in the coding sequence of the PAH gene. ${ }^{37}$ b) From the analysis of other mutations again identicalby-state yet on multiple haplotypes has come evidence for intragenic recombination in the $100 \mathrm{~kb}$ PAH gene; accordingly, these mutations (S67P, G 218V, V 245A and IV S12nt1) are identical by descent.

vi) Discovery of the recurrent $R 408 \mathrm{~W}$ and the $165 T$ mutation in $Q$ uebec, along with revealing geneaological reconstructions, ${ }^{19}$ led to enquiries about their E uropean origins and how they came to be markers of range expansion. The $\mathrm{R} 408 \mathrm{~W}$ mutation on haplotype 1 , and I65T on haplotype 9 , are now seen to cluster in North Western Europe along its A tlantic borders, ${ }^{50,51}$ the regions from which settlers of $\mathrm{New}$ France/Lower Canada largely came prior to 1945. vii) The profile of mutation types (Figure 2) at the $\mathrm{PAH}$ locus in the Q uebec poopulation is similar to that found world-wide and in particular to that reported for the U nited States; ${ }^{46}$ family studies have so far ruled out any de novo PAH mutation in Q uebec. The findings imply that demography and human history, rather than environmental mutagenesis for example, explain the PA H mutation profile in these $\mathrm{New}$ World populations. Nor is the frequency of unidentified PKU-causing mutations in the Q uebec sample exceptional; it may reflect a limitation of the DGGE method, but it is equally likely that these reclusive mutations could occur in the non-coding regions of the gene (although prior searches in the $5^{\prime}$ region of the $\mathrm{PAH}$ gene have been unfruitful on otherwise uninformative 'PKU' ' chromosomes. ${ }^{52}$

In summary, from a careful study of PAH mutations in a well-defined New World population (Q uebec), it has been possible to document molecular mechanisms generating genomic diversity (eg recurrent mutation and intragenic recombination) and to trace historical events underlying the genetic variation observed in the population (such as range expansion and genetic drift, during the past 400 years). Furthermore, our model shows how it might be possible, despite the difficulties inherent in extensive allelic heterogeneity for mutation diagnosis, ${ }^{39,40}$ to apply knowledge about population genetic variation to efficient prediction, treatment and prevention of a genetic disease.

\section{Acknowledgements}

Part of this work was submitted by KCC to the Faculty of Graduate Studies and R esearch, M CG ill U niversity in partial fulfilment of requirements for a Master's thesis. It was also presented, in part, at the A nnual meeting (29 October-4 N ovember 1996) of the A merican Society of $H$ uman $G$ enetics (C arter K et al A m J H um G enet 1996; 59: (Suppl.) A 30, A bst. p143, 1996). We thank our patients for their contributions to knowledge, Per Guldberg for our introduction to broad-range DGGE, Savio Woo, R andy E isensmith, and colleagues for their generosity with advice and reagents, Pardeep Kuarah for help with non-PKU H PA patients, G érard B ouchard, Claude Laberge, Ken Morgan, and Rima Rozen for advice and encouragement during this project. The work was supported in part by the Medical R esearch Council of Canada (MRC $G$ roup in Medical Genetics), the Networks of Centres of Excellence (Canadian Genetics Diseases Network), the Fonds de la Recherche en Santé du Québec (Réseau G énétique H umaine A ppliqué), the Interuniversity Institute for Population Research (IREP) and the Ketchum Fund. Lynne Prevost not only helps to curate the PAH mutation 
database but also controlled the electrons producing this 'manuscript'.

\section{References}

1 Crosby AW: Ecological Imperialism. The Biological Expansion of Europe 900-1900. Cambridge U niversity Press: Cambridge, 1986.

$2 \mathrm{M} \mathrm{CE}$ vedy $\mathrm{C}$, J ones $\mathrm{R}$ : A tlas of World Population $\mathrm{H}$ istory; Penguin Books, 1978, 283pp.

3 Charbonneau H, R obert N, Harris RC (eds): H istorical Atlas of Canada. vol. I: From the beginning to 1800. Toronto University Press: Toronto, 1987; The French origins of the $C$ anadian population 1608-1759. Plate 45.

4 G entilcore $R L$, M easner $D$, D oherty $D$ : The coming of the L oyalists. Plate 7. In G entilcore $R L$, M easner $D$, Walder $\mathrm{RH}$ (eds). Historical A tlas of Canada, vol. II The land transformed 1800-1891. Toronto U niversity Press: Toronto, 1993.

5 Cartwright D, MacPherson M : Population Composition. Plate 4. In Kerr D, H oldsworth D S, (eds). H istorical A tlas of Canada, vol. III, Addressing the Twentieth Century 1891-1961. Toronto U niversity Press: 1990.

6 Weaver J C, D eJ onge J, N orris D: Trans-A tlantic M igrations. 1831-1851. Plate 9. In G entilcore RL, M easner D, Walder R H, (eds). H istorical A tlas of Canada. vol. II, The land transformed 1800-1891. Toronto U niversity Press: Toronto; 1993.

7 Woo SL C et al: Cloned human phenylalanine hydroxylase gene allows prenatal diagnosis and carrier detection of classical phenylketonuria. N ature 1983; 306: 151-155.

$8 \mathrm{~K}$ wok SCM et al: Nucleotide sequence of a full-length complementary DNA clone and amino acid sequence of human phenylalanine hydroxylase. B iochemistry 1985; 24: 556-561.

9 Konecki DS et al: Structural characterization of the $5^{\prime}$ region of the human phenylalanine hydroxylase gene. B iochemistry 1992; 31: 8363-8368.

10 Lidsky $A$ et al: Extensive restriction site polymorphism at the human phenylalanine hydroxylase locus and application in prenatal diagnosis of phenylketonuria. A $\mathrm{m} \mathrm{J} \mathrm{H} \mathrm{um}$ G enet 1985; 37: 619-634.

11 Scriver CR, Kaufman S, E isensmith E, Woo SLC: The hyperphenylalaninemias. In Scriver $C R, B$ eaudet $A$ L, Sly WS, Valle D, (eds). The M etabolic and M olecular B ases of Inherited D isease. 7th edn. M cG raw Hill B ook Co: Place, 1995, pp 1015- 1075.

$12 \mathrm{G}$ oltsov A A et al: A ssociations between mutations and a VNTR in the human phenylalanine hydroxylase gene. A m J H um G enet 1992; 51: 627-636.

13 Goltsov A A et al: A single polymorphic STR system in the human phenylalanine hydroxylase gene permits rapid prenatal diagnosis and carrier screening for phenylketonuria. H um M olec G enet 1993; 2: 577-581.

14 Lichter-Konecki $U$, Schlotter $M$, Konecki D S: DNA sequence polymorphisms in exonic and intronic regions of the human phenylalanine hydroxylase gene aid in the identification of alleles. H um G enet 1994; 94: 307-310.

15 E isensmith R C, Woo SL C: U pdated listing of haplotypes at the human phenylalanine hydroxylase (PAH) locus. Letter to the Editor. Am J Hum Genet 1992; 51: 1445-1448.
16 Feingold J et al: Linkage disequilibrium in the human phenylalanine hydroxylase. Dev Brain Dysfunct 1993; 6: 26-31.

17 Nowacki P, Byck S, Prevost L, Scriver CR: The PAH mutation analysis consortium database: update 1996. N ucl A cids Res 1997; 25: 139-142.

18 John SWM et al: R ecurrent mutation, gene conversion, or recombination at the human phenylalanine hydroxylase locus: evidence in French-Canadians and a catalog of mutations. A m J H um G enet 1990; 46: 970-974.

19 Treacy E, Byck S, Clow C, Scriver CR: 'Celtic' phenylketonuria chromosomes found? Evidence in two regions of Q uebec province. E ur J H um Genet 1993; 1: 220-228.

20 Rozen $\mathrm{R}$ et al: Mutation profiles of phenylketonuria (PKU) in Quebec populations: evidence of stratification and novel mutations. Amer J Hum Genet 1994; 55: 321-326.

21 Lambert DM: The Genetic Epidemiology of $H$ yperphenylalaninemia in Quebec. Thesis submitted to the Faculty of Graduate Studies and R esearch, M CG ill U niversity, M ontreal 1994.

22 Bouchard G, DeB raekeleer $M$ : Histoire d'un gènome. Population et génétique dans l'est du Québec. In Bouchard G, DeBraekeleer M (eds): The Sillery, Q uébec, Presses de l'U niv. du Québec, 1991.

23 Bouchard G, Desjardins-O uellette M-A, Markowski $F$, Kouladjian K : L a distribution des patronymes au $Q$ uébec: Témoins des dynamiques de population. A nthropologie et Sociétés 1985; 9: 197-218.

24 Guldberg P, Henriksen K F, G üttler F: M olecular analysis of phenylketonuria in Denmark: $99 \%$ of the mutations detected by denaturing gradient gel electrophoresis. G enomics 1993; 17: 141-146.

25 Guldberg P, G üttler F: Mutations in the phenylalanine hydroxylase gene: method for their characterization. A cta Pediatr Suppl 1994; 407: 27-33.

26 Beutler $E$ et al: Mutation nomenclature: nicknames, systematic names, and unique identifiers. $\mathrm{H}$ um $\mathrm{M}$ ut 1996; 8: 203-206.

27 A d hoc Committee: U pdate on nomenclature for human gene mutations. Hum M ut 1996; 8: 197-202.

28 H oang L, Byck S, Prevost L, Scriver CR. (curators): PA H Mutation A nalysis Consortium D atabase: a database for disease-producing and other allelic variation in the human PA H locus. Nucleic A cids Res 1996; 24: 127-231.

29 King R C, Stansfield WD (eds).: A Dictionary of Genetics, 4th edn Oxford U niversity Press, New York, 1990.

30 Waters J, Parniak MA, Nowacki P, Scriver CR: In vitro expression analysis of mutations in human and rat phenylalanine hydroxylase: Exploring molecular causes of hyperphenylalaninemia. H um M ut 1997; 11: 4-17.

31 Carter, KC: Population genetic variation at the human phenylalanine hydroxylase locus. Thesis, McGill U niversity, Faculty of Graduate Studies and R esearch, M ontreal 1996.

32 Waters PJ et al: A nalysis of the [C.470G - >A; c.471A - >C ] ( $R 157 N$ ) mutation in human phenylalanine hydroxylase by in vitro protein expression in three systems: correlation with in vivo phenylalanine oxidation and phenylketonuria phenotype (A bstract). A m J H um G enet 1997.

33 Tyfield LA et al: Molecular basis of phenylketonuria in an English population. Dev Brain Dysfunct 1993; 6: 60-67. 
34 Dianzani I et al: Genetic history of phenylketonuria mutations in Italy. A m J Hum G enet 1994; 55: 851-853.

35 Zschocke J et al: N on-phenylketonuria hyperphenylalaninaemia in Northern Ireland: frequent mutation allows screening and early diagnosis. Hum Mut 1994; 4: 114-118.

36 Byck $S$ et al: E vidence for origin, by recurrent mutation, of the phenylalanine hydroxylase R 408W mutation on two haplotypes in European and Q uebec populations. H um M olec G enet 1994; 3: 1675-1677.

37 Byck S, Tyfield L, Carter K, Scriver CR: Prediction of multiple hypermutable codons in the human $\mathrm{PAH}$ gene: codon 280 contains recurrent mutations in Quebec and other populations. Hum Mut 1997; 9: 316-321.

$38 \mathrm{~K}$ ayaalp E : Human PAH mutations and hyperphenylalaninemia phenotypes: a meta-analysis of genotype-phenotype correlations. A m J H um G enet 1997; 61.

39 Cotton RGH: Current methods of mutation detection. M ut Res 1993; 285: 125-144.

$40 \mathrm{G}$ rompe $\mathrm{M}$ : The rapid detection of unknown mutations in nucleic acids. N at G enet 1993; 5: 111-117.

41 Weiss K M : Is there a paradigm shift in genetics? Lessons from the study of human diseases. Molec Phylogenetics and E volution 1996; 5: 259-265.

42 Scriver CR, B yck S, Prevost L, H oang L: PA H M utation A nalysis Consortium: variation in the human genome. John Wiley and Sons: Chichester, 1996; The phenylalanine hydroxylase locus: a marker for the history of phenylketonuria and human genetic diversity. pp.73-96.

43 Penrose LS: Phenylketonuria. A problem in eugenics. $L$ ancet 1946; 1: 949.

44 Ramus SI, Treacy E P, Cotton RG H: Characterization of phenylalanine hydroxylase alleles in untreated phenylketonuria patients from Victoria, Australia: O rigin of alleles and haplotypes. Am J Hum Genet 1995; 56: 1034-1041.
45 Perez $B$ et al: Presence of the Mediterranean PKU mutation IV S10 in Latin A merica. Hum Molec G enet 1993; 2: 1289-1290.

46 Guldberg P, et al: Phenylalanine hydroxylase gene mutations in the $U$ nited States. $R$ eport from the $M$ aternal PKU Collaborative Study. A m J H um G enet 1996; 59: 84-94.

$47 \mathrm{~A}$ badie $\mathrm{V}$ et al: Molecular basis of phenylketonuria in France. D ev Brain Dysfunct 1993; 6: 120-126.

48 Lyonnet $\mathrm{S}$ et al: Time and space clusters of the FrenchCanadian M IV phenylketonuria mutation in France. A $\mathrm{m}$ J H um G enet 1992; 51: 191-196.

49 H eyer $E$, Tremblay $M$ : Variability of the genetic contribution of Quebec population founders associated to some deleterious genes. A m J H um G enet 1995; 56: 970-978.

$50 \mathrm{E}$ isensmith R C: R ecurrence of the R $408 \mathrm{~W}$ mutation in the phenylalanine hydroxylase locus in E uropeans. A m J H um Genet 1995; 56: 278-286.

51 Zschocke J, M allory JP, Eiken HS, Nevin NC: Phenylketonuria and the peoples of Northern I reland. Human G enet 1997; 100: 189-194.

52 Svensson E et al: Three polymorphisms but no diseasecausing mutations in the proximal part of the promotor of the phenylalanine hydroxylase gene. Eur J Hum Genet 1993; 1: 306-313.

53 E isensmith R C, Woo SL C: U pdated listing of haplotypes at the human phenylalanine hydroxylase (PA H ) locus. A m J H um G enet 1992; 51: 1445-1448.

54 Bénit $P$ et al: Novel frame shift deletions of the phenylalanine hydroxylase gene in phenylketonuria. $\mathrm{H}$ um M olec Genet 1994; 3: 675-676.

55 Bénit $P$ et al: Five novel missense mutations of the phenylalanine hydroxylase gene in phenylketonuria. $\mathrm{H}$ um M ut 1994; 4: 229-231. 